Original Article

Received/Accepted Dates

$17.12 .2021 / 28.02 .2022$

DOI 10.52096/usbd.6.24.9
International Journal of Social Sciences

Uluslararası Sosyal Bilimler Dergisi

www.sobider.net

ISSN: 2548-0685

\title{
Ĕ̆itim Kurumlarında Öğretmenlerin Meslekî Tükenmişlik Yaşamalarına Etki Eden Faktörlerin İncelenmesi
}

Serkan Kaynar

Millî Eğitim Bakanlığı Eğitim Yöneticisi

serkankaynar@windowslive.com

ORCID:0000-0001-6442-1826

\section{Özet}

Çalışma hayatında sıkça karşılaşana bir sorun olan tükenmişliğin en yaygın görüldüğü mesleklerin başında hiç kuşkusuz öğretmenlik mesleği gelmektedir. Tükenmişliğin öğretmenin kendisi, öğrencileri, ebeveynleri ve eğitim yapısı üzerinde birçok olumsuz etkisi vardır. Mesleki olarak tükenmiş öğretmenin öğrencisi ile etkileşimi nitelik ve nicelik olarak azalmakta, iş tatmini azalmakta, iş performansı zayıflamaktadır, çalışmakta isteksizlik ve işten vazgeçme isteği oluşmaktadır. Sonuç olarak, tükenmişlik yaşayan öğretmenler, fiziksel ve zihinsel sağlık sorunları ortaya çıtıkça işe karşı olumsuz tutum ve davranışlar geliştirmektedirler.

Anahtar Kelimeler: Eğitim Kurumları, Meslekî Tükenmişlikler, Öğretmenlerde Meslekî Tükenmişlik

\section{Investigation of Factors Affecting Teachers' Experience of Professional Burnout in Educational Institutions}

\section{Summary}

One of the professions where burnout, which is a common problem in working life, is most common, is undoubtedly the teaching profession. Burnout has many negative effects on the teacher himself, his students, their parents, and the educational structure. The interaction of the professionally exhausted teacher with the student decreases in terms of quality and quantity, job satisfaction decreases, job performance 
weakens, reluctance to work and the desire to quit work. As a result, teachers experiencing burnout develop negative attitudes and behaviors towards work as physical and mental health problems arise.

Keywords: Educational Institutions, Professional Burnout, Professional Burnout in Teachers

\section{Giriş}

Öğretmenler değişik sosyal, iktisadi ve teknoloji gelişimi ve ilerlemelerine bağlı değişen eğitimsel kavrayışları sebebiyle meslek tükenmişliği yaşamaktadır (Gündüz, 2015: 29).

Öğretmenler, sosyal, ekonomik ve teknolojik gelişmeler doğrultusunda değişen eğitim ve öğretime yaklaşımları nedeniyle tükenmişlik yaşamaktadırlar. Literatürün gözden geçirilmesiyle, öğretmen tükenmişliğini etkileyen en önemli arka plan faktörlerinin çevresel, kişisel ve meslekteki kalitesi olduğunu ortaya koymaktadır (Kırılmaz, Çelen ve Sarp, 2017: 21).

Eğitim ve öğretimde öğretmenler, öğrenci-öğretmen ve okul ve aileleri arasındaki sorunlar, meslektaşlar arasındaki sorunlar, disiplin problemleri, eksik fiziki imkanlar, aşırı bürokratik çalışma, toplumsal eleştiriler, yoğun sınıf mevcutlarının oluşu, öğrencilerdeki gelişim eksikliği, eğitim üzerindeki toplumsal ve siyasi baskılar gibi yoğun sorunlara bağlı olarak tükenmişlik yaşayabilmektedirler (Kahyalığlu ve Yangın, 2017: 44).

Ayrıca müfredatta uzun vadeli bir planlama yapılamaması, aşırı iş yükünün olması, tatmin etmeyen ücret, idari yönden yeterli desteği görememek, amirinin ve müfettişlerin takdirini kazanamamak, öğretmenin sınıfın kontrolünü kaybettiğine dair inanç ve yönetim kararlarına katılamama durumu, öğretmenlerin mesleki becerilerine ilişkin bilgi eksikliği, öğretmenin yetersiz başarı algısı, meslektaşlarından ve idari yönteminden yeterli desteği görememek, görev çatışması ve belirsizliği, öğrencinin ilgisizliği, düzeni bozan ve zarar veren davranışları gibi aşırı problematik durumlara paralel olarak da tükenmişlik yaşayabilmektedirler (Moragil, Seçken ve Yücel, 2016: 14).

Öğretmenin mesleki olarak işe uygun olması ve öğrencisini kontrol etmekte güçlük çekmesi tükenmişliğe neden olan etkenlerden bazılarıdır. Eğitim ve öğretim çalışmaları ile ilgili kararlarda eğitimcilerin etkisinin ve sorumluluğunun son zamanlarda azalmış olması da öğretmen tükenmişliğine yol açabilmektedir (Sandık, 2009: 29). 
Öğretmenin ortaya çıkan sorunlarla baş edebilmesi ve sorunlara yönelik işe yarar çözümler bulabilmesi, iş becerileri ile doğrudan ilişkilidir. Yeterlik düzeyi düşük öğretmenin yüksek yeterlik düzeyine sahip öğretmene göre daha fazla tükenmişlik yaşamasının nedeni, bu öğretmenin stresörler karşısında sorunu çözmeye odaklanmaması, tam tersine sorun odağına yaklaşmaktan kaçınmasıdır (Kanner, 2017: 37).

$\mathrm{Bu}$ çalışmada öğretmenlerin mesleki tükenmişliğinin ortaya çıkış nedenleri genel hatlarıyla muhtasar bir şekilde incelenmiştir.

\section{Öğretmenlerin Mesleki Tükenmişliğinin Sebepleri}

Öğrencide istenildik tutumun ne olduğu hususunda topluluk, kültür, birey ve yaşanılan çevrenin değişik zaman diliminde yaşayan fertlerin görüşleri açısından farklılık bulunmaktadır (Ertaş, Kurcali ve Teksin, 2016: 22).

Başar, davranımın istenir bulunup bulunmamasının ölçütünün davranımı yapanlara, karşısında kişilere, davranımın meydana geldiği ortamın özeliklerine ve topluluk kültür ve değer yargılarına göre şekillendiğini ifade etmiştir (Başar, 2007: 39).

50 sene öncesinde ilk okulda öğrenciye susun, oturun, ellerinizi sırada kenetleyin tarzında ikazlar çok sıkça verilir iken günümüz koşullarında öğrencinin derste aktif olması, kendini özgür bir şekilde ifade etmesi öne çıkarılmıştır. Dersine zamanında çalışan, büyüğüne ve arkadaşına saygı gösteren öğrencinin tutumu dahi diğer öğretmenlerce değişik tarzda değerlendirilebilmektedir (Yiğit, 2007: 42).

Öğrencide gözlenmekte olan sorunlu davranışlar, sınıf seviyesinde ve her yaşta olağan gelişimler göstermekte olan bireylerde ve özel eğitimlere ihtiyacı bulunan bireylerde gözlemlenebilmektedir (Torrun, 2005: 19).

Sorunlu davranışların tanımlarıyla alakalı değişik bakış açıları bulunmaktadır. Eker ve Arkar hem o çocuğun hem de farklı çocukların öğrenmesine mühim ölçüde etki eden ve öğretmenin öğrenciye etkin biçimde öğretimlerine engel teşkil eden tutumuna sorunlu davranış olarak tanımlama yapmıştır (Eker ve Arkar, 2005: 16). 
Sorunlu davranışın bu davranımı yapan bireye, çevrelerindekine, akranlarına, anne-babasına ve öğretmene negatif tesirlerinin bulunduğu bir çok çalışmada kanıtlanmıştır (Başar, 2007: 17; Ertaş, Kırcali, Teksin, 2016: 24). Bireylerdeki sorunlu davranışların sosyokültürel, eğitim ve sıhhi alanlarda sorunlara sebep olunmasından ötürü birey ve topluluklara maliyetleri fazladır (Celep, 2009: 18).

Başar, sorunlu davranışların sınıf içerisinde eğitimin ve öğretimin hedeflerinin gerçekleşmesine engel olduğu, sınıfın faaliyetlerinde aksamaya neden olduğu ve sınıfın ortamının bozulduğunu ifade etmiştir (Başar, 2007: 39).

Sucuoğulu, Gümüş ve Peşkin (2001), davranışsal sorunların hem çocuğun farklı beceriler öğrenme durumuna, hem mevcut becerilerini kullanmasına engel olur iken hem de çevresiyle sosyokültürel etkileşimine ve topluluk uyumuna da negatif açıdan etki ettiğini ifade etmişlerdir (Sucuoğulu, Gümüş ve Peşkin, 2001: 41).

Ertaş (2016), bu düşünceyi desteklemek suretiyle sorunlu davranışta bulunan bireyin bu davranışından ötürü bilimsel çalışmalara tam olarak odaklanmayacaklarını, bu sebep ile de eğitimim kanlarından yaşıtları gibi faydalanamayacaklarını ve farklı becerileri elde edemeyeceklerini ifade etmiştir (Ertaş, 2016: 52).

Diğer yandan bu bireylerin sergilediği sorunlu davranış sebebi ile yaşıtları tarafindan dışlandıklarını, bu neden ile gurup faaliyetine katılamamak suretiyle yaşıtlarından öğrenebileceği beceriden de mahrum kaldığını ifade etmiştir.

Problemli davranışların problemli davranışta bulunan bireylere ve akranına negatif tesirleri olduğu kadar sınıf öğretmenlerine de negatif tesirleri bulunmaktadır. Sınıfın içerisinde sorun davranışlarda bulunan öğrencileri olan öğretmenlerin, sorunlu davranışları azaltma amacıyla, program geliştirme ve programları uygulama amacıyla çaba ve epeyce vakit harcama durumlarında kalacaklardır (Başar, 2007: 35).

Dolayısı ile sorunlu davranışları ortamdan kaldırma amacıyla harcanılan çaba ve vakit, öğrenim amacıyla ayırılacak zaman ve çabanın kaybolmasına neden olacaktır (Kanner, Yelice ve Şekercioğulu, 2017: 39).

Sorunlu davranışlar öte yandan ailenin içerisinde de problemler yaşanılmasına ve aile fertleri içerisinde negatif ilişkiler oluşmasına da sebep olmaktadır (Yıldız, Karaoğlu ve Soran, 2016: 18). 
Yetkin bir sınıf kontrolü için öğretmenin öncelikle sınıfındaki problemli davranışı ortaya koyması (Zengin, 2017: 24), sonrasında sorunlu davranışların altındaki sebepleri anlamaya gayret göstermelidir (Başar, 2007: 41).

Öğrencide gözlenmekte olan sorunlu davranışlar, kendi özeliklerinden kaynaklı olabileceği gibi sınıf durumunun özelliğinden ve ev ortamındaki yaşantıdan da kaynaklı olabilir (Türnülü, 2009: 37). Sorunlu davranışların meydana gelmesine etki eden etkenlerinse okul içi ve dışı etkenler şeklinde iki başlık altında irdeleme mümkündür.

\section{Okul İçi Etkenler}

Öğrencide gözlenmekte olan sorunlu davranış okul dışı faktörler kadar öğrencinin özelikleri, eğitimsel program, öğretimsel yöntemler ve materyaller, öğretmenin tutum ve davranışları gibi okul içi faktörlerle ilgilidir.

\section{a.Öğrencinin Özelikleri}

Öğrencinin değişik çevreye ve hayat şekillerine, değişik fizikî, zihni, sosyokültürel özeliklere ve ilgilere, yeteneklere ve zekâ ölçütlerine haiz olması onun değişik davranım göstermesine sebep olmaktadır (Ünüsal, 2006: 32).

Öğrenci, kendini sevgiden ve değerden mahrum görme; öne çıkma ve karşıt tepki oluşturma; başkasının eleştirisi, hakaret etmeleri, azarlamaları, saygısızca davranımlar sergilemeleri, alaycı konuşmaları etmeleri; aidiyet hissi, topluluğa katılma istekleri; öğretmenlerden, sınavdan veya sınıfında konuşmaktan korkması, okulda çalışmayı eğlencesiz bulması gibi sebepler ile sınıfında istenilmeyen davranış gösterebilmektedir. Öğrenci tanınmak, fark edilmek, kıymet görmek gibi gereksinmelerden ötürü değişik davranışsal sorunları sergileyebilir (Kanner, 2017: 63).

Başar, bilimsel yeterliliği, etkileşim seviyesi, sosyokültürel becerileri yetersiz, toplumsal açıdan yalnızlık duyan, dostu bulunmayan, sosyokültürel açıdan negatiflik içerisinde bulunan, okulunu 
benimsemeyen öğrencinin okuldaki uyumunda zorlandığını, uygun bulunmayan davranışa çokça yöneldiğini ifade etmiştir (Başar, 2007: 29).

Öğrencinin başarma seviyesinin yetersiz bulunması, dilsel gelişmelerdeki sorunlar, hissel ve öğrenimsel bozukluklar, gelişim gerilikleri gibi etkenler çocuğun sorunlu davranışlar göstermesine sebep olabilir (Atıc1, 2010: 52).

\section{b.Eğitim Programı}

Öğrencinin ilgisi ve gereksinimi yönünde hazırlanmamış eğitimsel programlar, öğrencinin derste sıkılmasının ve motivasyon azalmasının sebeplerindendir (Kanner, 2017: 41).

\section{c.Öğretim Yöntemleri}

Öğretmenin uygun öğrenim yöntemi ve tekniğini kullanmaması, uyguladığı öğrenim yöntemi ve tekniğini geliştirmemesi, öğrencisinin ilgisine ve ihtiyacına dönük faaliyetini planlamaması öğrencinin sınıfın içerisinde istenilmeyen davranımına yol açabilmektedir (Türnülü, 2009: 36).

\section{d.Öğretmenlerin Tutum ve Davranışları}

Sınıf ortamlarının veya sınıf iklimlerinin oluşturulmasında ve öğrenci başarısı ile öğrencide gözlenmekte olan problemli davranışın meydana gelmesini etkilemede öğretmenin takınacağı tavır mühim bir tesire haizdir. Öğrenciyle öğretmenin ilişkisinin niteliği, akademi başarısına ve öğrenci davranışına tesir etmektedir (Sandık, 2009: 19).

Öğretmenlerin kişisel farklıklara karşı hassas, sınıfın yönetim becerilerinde yetkin, öğrencinin bilimsel ve bilimsel olmayan davranışı için amaç ve beklenti oluşturan, ödevleri uygun veren, disiplini tutarlı şekilde uygulayan, yetkin öğrenim yöntemi ve tekniği kullanan, pozitif anlamda 
örnek olan, sıcakkanlı, sevimli, hoşgörülü tavrıyla öğrencisinde istendik davranış kazandırması bakımından mühimdir (Demircitaş, 2009: 61).

Bir çok araştırman, problemli davranışın oluşmasını eğitimcinin çocukların bu tutumunu tanımak, anlamak ve ehemmiyetini kavramak hususundaki yetersizliğine bağlamışlardır (Eripek, 1990: 11).

Tertemiz, öğretmenin öğrenciler içerisinde ayırım yapması, öğrenim materyalini vaktinde hazır etmemesi, öğrenciye devamlı nasihatler vermesi, derse vaktinde başlayarak vaktinde bitirememesi gibi sınıfın yönetimi becerisi ile alakalı problemlerin öğrencide davranışsal sorunlara sebep olacağını ifade etmiştir (Tertemiz, 2009: 72).

Öğretmenin bireysel özelikleri, kendine güven eksiklikleri, mesleki tükenmişlikleri, başaramama endişesi, kişisel sorunlar da sınıfın içerisindeki otorite sıkıntılarının temel nedenleri olabilir; dolayısı ile de öğrencide sorunlu davranışa neden olabilir.

Öğretmenlerin öğrencilerinin kendi güvenlerine hasar verebilecek tipteki davranışları; küçümsemek, alay etmek, sabırsız davranmak, hoşgörülü olmamak, sinirlilik hali, fizikî ya da sözsel saldırılar türündeki davranışı öğrencilerde saldırgan ve kızgın olma gibi davranışlar meydana getirmektedir (Tertemiz, 2009: 71).

Dolanay, öğrencilerde gözlenmekte olan sorunlu davranışın meydana gelmesine sebep bulunan öğretmen davranışını, devamlı negatif olmak, baskıcı bir durum sürdürmek, olaylar karşısında fazla tepkisel davranmak, öğrencilerin beceri düzeyinin farkında olamama gibi davranış olarak sıralamıştır (Dolanay, 2010: 18).

\section{Okul Dışı Etkenler}

Öğrencilerin sorunlu davranışının meydana gelmesiyle alakalı okul dışı faktörler öğrencilerin fizyolojik durumu, aile içerisindeki yaşantıları, topluluk etkisi, akran ve medya şeklinde siralanmaktadir. 


\section{a.Fizyolojik Durum}

Öğrencilerin sınıf içi sorunlu davranışını hastalık, beslenme bozukluğu, genetiksel sorunlar, fizikî sakatlık, kullanılan ilaç ve tıbbi cihazlar gibi etkenler etkilemektedir (Kanner, 2017: 49). Alerji rahatsızlıkları, uykusuzluklar gibi sıhhi sorunlar öğrencinin arkadaşları ile ve öğretmeni ile etkileşimini etkilemektedir, öğrencide istenilmeyen davranıma sebep olmaktadır(Sandık, 2009: 28).

Kırılmaz, Çelen ve Sarp, fizyoloji durumunun öğrencinin sorunlu davranışının altında mühim bir sebep bulunduğunu; görme-işitme engelleri, ortopedi ve zihni engeli bulunan çocuğun sınıfın içerisinde kızgınlık ve saldırganlık gösterebileceğini; kitapları, defterleri veya sırayı çizmek, sınıfın içerisinde kargaşa çıkarmak gibi davranışsal bozukluklara yönelik işaretler gösterebileceğini belirtmişlerdir (Kırılmaz, Çelen ve Sarp, 2017: 28).

\section{b.Aile}

Öğrencide gözlenmekte olan sorunlu davranışın mühim sebeplerinden biriside çocukların davranışlarının biçimlenmesinde esas katkısı bulunan aile fertlerinin tutumları ve davranışıdır (Moragil, Seçken ve Yücel, 2016: 17).

Kırılmaz, Çelen ve Sarp (2017), boşanan yahut aile içi kavganın fazlaca yaşandığı, yeterli sevgi ve alaka gösterilmeyen ailedeki çocuğun, Dönmezler (2001) ev içerisindeki yoğun kontrol ve baskının, ev içerisindeki fazlaca koruyuculuk bireyde istenilmeyen davranışa sebep bulunduğunu ifade etmektedir. Sosyokültürel ve ekonomi açısından dezavantaj gösteren bireylerde de davranışsal sorunların görünme oranı daha fazladır (Atıcı, 2010: 36).

\section{c.Toplum}

Çocukların içerisinde yaşamakta olduğu topluluklar da çocukların davranışı üstünde mühim tesiri bulunmaktadır. Sandık, karşı karşıya gelinen sorunları çokça kargaşa ve zorluk kullanmak 
suretiyle çözmek eğiliminde bulunan topluluk kavrayışının çocuğun sinirlenmesine ve saldırgan hale bürünmesine sebep bulunduğunu ifade etmiştir (Sandık, 2009: 30).

\section{d.Arkadaş Çevresi}

Çocuğun davranışının biçimlenmesinde mühim bir rolü bulunan bir faktörde, arkadaşların ve akranların oluşturduğu çevredir. Negatif arkadaş ilişkisi çocuğun istenilmeyen davranışı modellemesine ve gerçekleştirmesine sebep olmaktadır. Öte yandan öğrencinin okuldaki arkadaşlarınca kabullenilmemesi, alaycılığa maruz kalması hususunda davranışsal sorunlarının meydana gelmesine sebep olmaktadır (Kanner, 2017: 47).

\section{e.Medya}

Şüphesiz, cebir içermekte olan unsurların yoğunlukta yayınlandığı ana akım ve sosyal medya araçlarının çocuğun sorun davranışının meydana gelmesinde katkısı fazladır.

Kahyalığlu ve Yangın, duygusal yoksunluğu ve öğrenimsel geriliği bulunan çocuğun bilgisayar, akıllı telefon ile televizyon programındaki hakikî ve düşsel durumları ayırt edemediğini ifade etmiştir (Kahyalığlu ve Yangın, 2017: 22). Bu durum, çocuklara televizyon bilgisayar ve akıllı telefon programları izlettirilir iken çok seçici olma gerektiğini meydana çıkarmaktadır.

\section{Sonuç}

Eğitimin niteliğini arttırma suretiyle nitelik sahibi öğrenci yetiştirme gibi mühim vazifeleri bulunan öğretmenin idare tarafından yeterli desteği görememesi, öğrencinin ilgisiz kalması, başarılı olamaması, negatif davranışları, meslektaşlarının negatif tavırları, okul ile aile arasındaki işbirliği yetersizliği, mesleki yoğunluk sebepleri kadar bireylerin demografi özelikleri (yaşı, cinsiyeti, medenî durumu), karakter özelikleri (endişe düzeyi, denetimsel odakları, dayanıklıkları, 
kapasiteleri) ve haiz bulunduğu farklı özelikleri sebebi ile mesleki tükenmişlikler yaşadığı görünmektedir.

Eğitim kurumlarında çalışmakta olan öğretmen, çevrenin öğrencinin gelişmesiyle alakalı realist bulunmayan beklentileri ile didişmek, mesai arkadaşlarından uzak durma gibi problemler nedeni ile mesleki tükenmişlikler yaşayabilmektedir.

Ülkemizdeki ortam düşünüldüğünde özel eğitimde çalışmakta olan öğretmenlerin birçoğunun özel eğitimin haricindeki sahalarda eğitim gördüğü ve özel eğitimde pek donanıma sahip olmadı̆̆ 1 görülmektedir. $\mathrm{Bu}$ neden ile, özel eğitimde çalışmakta olan öğretmen çalıştığı gurubun özelliklerine tamamıyla hakim olmadığ bilgi birikimi olmadığı için gerginlik ile mesleki tükenmişlikler yaşayabilmektedir.

Tükenmişliklerin minimal düzeyde yaşandığı durumlarda bile, bireylerin hayat işlevinin etkilenilmesi, öğretmence verilmiş olan eğitimsel hizmetin niceliği ve niteliğinde belirgince bozulma görünmesi nedeni ile öğrencinin gelişiminde etkisi olan öğretmenin mesleki tükenmişlikler düzeyini etki altına alan etmenlerin araştırılarak, tükenmişliği engelleme çalışması yapılmasını gerektirmektedir. Böylelikle kaliteli öğretmenin görev yerinde uzun yıllar çalışması sağlanacak, tükenmişlik hissinin sebep olduğu iktisadi ve topluluksal engellemelerin önüne geçilecektir.

$\mathrm{Bu}$ açıdan yurtiçi ile yurtdışı literatür irdelendiğinde millî eğitim kurumlarında görevli öğretmenlerin mesleki tükenmişlik düzeyini, mesleki yeterliliğini, mesleki desteksel algısını ve öğrencinin sorun davranışına dönük değerlendirmesini beraber ele almak suretiyle model olarak irdeleyen çalışmalar görülmemiştir.

$\mathrm{Bu}$ özelliğiyle bu çalışma gerek milli gerekse de uluslar arası literatürüne destek sağlayacak ve yeni çalışmaların gerçekleştirilmesine yardımcı olacaktır.

Öğretmenlerin mesleki tükenmişlikteki değişkenliklerin araştırılması, gerek topluluksal gerekse iktisadi bakımdan tükenmişliklerin meydana getirdiği negatif neticeleri engellemeye neden olacaktır.

Öğretmenin tükenmişlikler yaşamasını engelleme ve hayat kalitesini arttırma amacıyla öğretmenin yetiştirmesi, istihdamı ve gelişimini teşvikle esaslı bazı tedbirlerin yerine getirilmesi gerekir. 
Öncelik ile öğretmenin henüz üniversite eğitimi esnasında onu yetkin öğretmen becerisi ile kuşatacak eğitimsel program yönünde öğretim görmesi gerekmektedir.

Mesleğine ilk defa başlayan öğretmene hizmetin öncesi ve sırasında öğretmenlik mesleğinde karşılaşabileceği veya karşılaştığı esas problemlere yetkin çözümler üretebilme, yetkin mücadele etme, yetkin empati kurmak becerisi kazandırma çabasına dönük destek hizmeti verilmeli ve verilen hizmetin yararlılığı sınanmalıdır. Benzer eğitimler hizmet yılı fazla olan öğretmenlere de sunulmalıdır.

Çalışmakta olan öğretmenin ihtiyaçlarının idare tarafından belirlenerek kurumun fiziksel ile sosyal şartlarının geliştirilmesi, öğrenimi kolay hale sokacak yardım hizmetinin sunulması öğretmenin yaptığı işten keyif almasını arttıracak bir tedbir biçiminde de düşünebilir.

\section{Kaynakça}

Acar, Ç. ve Batu, S. (2010). Özel Eğitim Öğretmeninin Sınıfında Karşı Karşıya Geldiği Sorun Davranışla İlgili Görüş ve Önerileri. 10. Ulusal Özel Eğitim Kongresi Bildirileri, 86-95.

Akbaş, A. ve Çelikkaleli, Ö. (2014). Sınıf Öğretmenlerinin Tükenmişliklerinin Cinsiyetlere, Öğrenim Türlerine ve Üniversitelere Göre İncelenilmesi. Mersin Üniversitesi Eğitim Fakültesi Dergisi, 1 (2), 98-110.

Akçalımete, G., Kanner, S. ve Sucuoğulu, B. (2010). Öğretmende Tükenmişlik İş Doyumu ve Kişilik. Ankara: Nobel Yayın Dağııım.

Akıncı, S. (2014). Öğretmenin Tükenmişlik Düzeyinin Işs Doyumlarına Etkisi. Yayınlanmamış Doktora Tezi, Akdeniz Üniversitesi Sosyal Bilimler Enstitüsü, Antalya.

Altunçekiç A., Yaman S. ve Koray Ö. (2015). Öğretmenlerin Tükenmişlik Seviyesi ve Sorun Becerisi Konusunda Çalışma. Kastamonu Eğitim Dergisi, 13 (1), 93-102.

Ataman, A. (2009). Sinıfta Davranış Problemi ve Tedbirler, L. Küçükahmet, (Editör). Sınıf Yönetiminde Yeni Davranışlar, 171-191. Ankara: Nobel Yayınları. 
Avşaoğlu, S., Denizli, M.E. ve Karaman, A. (2015). Öğretmende Hayat Doyumu, İş Doyumu ve Mesleki Tükenmişlik Düzeyinin İncelenmesi. Selçuk Üniversitesi Sosyal Bilimler Enstitüsü Dergisi, 14, 115-129.

Başar, H. (2007). Öğretmenin Sınıf Yönetimi Tarzları. Ankara: Önder Matbaacılık.

Büyükçeöztürk, Ş. (2017). Sinıf Yönetimi El Kitabı: Çalışma, Uygulama ve Yorum. Ankara: Pegem Yayınları.

Cemaloğlu, N. ve Kayabaşı, Y. (2017). Öğretmenlerin Sınıf Yönetiminde Uyguladığı Disiplinel Modellemesi. Gazi Ĕ̈itim Fakültesi Dergisi, 27 (2), 123-155.

Çam, O. (2000). Öğretmende Tükenmişlik ve Çeşitli Değisşkenlere Göre İncelenmesi. Yüksek Lisans Tezi, Ege Üniversitesi Sosyal Bilimler Enstitüsü, İzmir.

Çiftçi, İ. ve Tabak, Ö. (2007). Öğrencide Görünen Sorun Davranışın Belirlenmesi. Eskişehir: VII. Özel Eğitim Günleri’nde Sunulan Bildiri.

Demir, Y. (2017). Sinlf Öğretmeninin Karşı Karşıya Gelinen Sorun Davranışa Karşı Başetme Stratejisi. Yüksek Lisans Tezi, Çankırı Üniversitesi Sağlık Bilimleri Fakültesi, Çankırı.

Diken, İ.H, ve Bal, A. (2018). Genç Yaşta Tükenmişlik Sendromları. The 26th Teacher Educatorsfor Children With Behavior Disabilities (TECBD) Conference, Tempe, Arizona, USA.

Ergin, C. (2002). Öğretmende Tükenmişlik ve Meslach Tükenmişlik Envanterinin Uyarlanmasl. 7. Psikoloji Kongre Kitabı. Ankara: Psikologlar Derneği Yayınları.

Gençer, A. (2018). Öğretmenlerin Mesleki Tükenmişlik Düzeyi. Yüksek Lisans Tezi, OÜ Sağlık Bilimleri Fakültesi, Eskişehir.

Girgin, G. ve Baysallar, A. (2015). Öğretmen Akademisi Bülteni, 4 (4), 172-187.

Gökdağ, M. (2006). Esas Eğitim Öğretmeni İle Öğrencinin Güdü Düzeyi İle Öğrenci Öğretmen Özelikleriyle İlişkileri. Yayınlanmamış Yüksek Lisans Tezi, DE Üniversitesi, Eğitim Yönetimi Enstitüsü, İzmir.

Gözütok, F.D. (2003). Okulda Bazı Dayak Uygulamaları. Çağdaş Eğitim, 186, 7-10.

Gündüz, B. (2015). İlköğrenim Öğretmeninde Tükenmişlik. Mersin Üniversitesi Eğitim Fakültesi Dergisi, 1 (1), 152-166. 
Izagar, H. (2010). Okul Yöneticilerinin Tükenmişlik Düzeyi. Kuramda ve Uygulama sahasında Eğitim Yönetimi Dergisi, 27, 335-340.

Kanner, S., Şekercioğulu G. ve Yelice, B. (2011). Öğretmenlerin Tükenmişlik Algıları ve Çocuğun Sorun Davranışları. Yayınlanmamış Çalışma Raporu. Ankara Üniversitesi, Eğitim Bilimleri Fakültesi, Ankara.

Kanasar, N. (2015). Tükenmişlik Düzeyinin Çalışılması: Kavramlar, İlkeler, Yöntem ve Teknikler. İstanbul: Nobel Yayın Dağıtım.

Kaşıç̧1, D. (2009). Mesleki Tükenmişlik Düzeyinin Çok Boyutlu Olarak Incelenmesi. Yüksek Lisans Tezi, SDÜ Eğitim Bilimleri Fakültesi, Isparta.

Maraşl1, M. (2015). Lise Öğretmenlerinin Tükenmişlik Düzeyi. Türk Tabipleri Birliği Dergisi, 23 (3), 27-33.

Murat, M. (2009). Sınıf Öğretmenlerinde Tükenmişliklerin İncelenmesi. Doktora Tezi, Karadeniz Teknik Üniversitesi Sosyal Bilimler Enstitüsü, Trabzon.

Özkan, S. (2018). Öğretmenin Tükenmişlik ve Depresyon Düzeyinin İncelenmesi. Yüksek Lisans Tezi, A.Ü. Eğitim Bilimleri Fakültesi, Ankara.

Özyürek, M. (2006). Sinıf Yönetimi. Ankara: Karatepe Yayınları.

Sandık, F. ve Doğanay, A. (2017). Sınıf İçinde ve Dışında İstenilmeyen Davranışlar. Ç.Ü.Sosyal Bilimler Enstitüsü Dergisi, 6 (1), 539-560.

Sucuoğulu, B. ve Kulotlu, N. (2006). Özürlü Çocuklar İle Çalışmakta Olan Öğretmende Tükenmişliklerin Değerlendirilmesi. Türk Psikoloji Dergisi, 10 (36), 44-60.

Şaherenler, S. ve Görgüllü, Ö. (2009). Tükenmişlik Nedir? Bir Uygulama. S.D. Ü. Ĕ̌gitim Fakültesi Dergisi, 5 (1), 87-102.

Tertemiz, N. (2009). Sınıf Yönetimi ve Disiplin. L. Küçükahmet (Ed), Sınıf Yönetimi, Ankara: Nobel Yayın Dağıtım, 49-69.

Tuğrul, B. ve Çelik, E. (2018). Anaokulu Öğretmeninde Tükenmişlik. A.Ü. Ĕ̆gitim Bilimleri Dergisi, 12 (2). 
Tülkaya, S. (2009). Tükenmişlik Ölçeğinin Geçerlik ve Güvenirlik Yönünden Geliştirilmesi. Ulusal Psikoloji Danışma ve Rehberlik Kongre Kitabı, Ankara.

Türk, A. (2016). Öğretmende Tükenmişlik. Europe Journalist of Specialist Needal Educations, 20 (2), 215-229.

Türnülü, A. (2009). İlköğrenimde Sınıf İçi İstenmeyen Davranış ve Sebebi. Yaşadıkça Eğitim, 64 (99), 30-34.

Ünüsal, P. (2006). Eğitim Kurumlarında Algılanan Tükenmişliklerin İşlevlerine, Kaynaklarına, Cinsiyet ve Mesleğe Göre İncelenişi. IX. Ulusal Psikoloji Kongresi Bilimsel Çalışmalar, Türk Psikologlar Derneği, 315-325. 